\title{
Breeding structure of natural populations of Drosophila buzzatii: effects of the distribution of larval substrates
}

\author{
Richard H. Thomas* and \\ J. Stuart F. Barker
}

Department of Animal Science, University of New England, Armidale, NSW 2351, Australia.

The population structure of several Australian populations of the cactophilic Drosophila buzzatii was investigated, with seasonal samples from two populations analyzed for six polymorphic allozymes. Significant inbreeding throughout the year was detected in both populations, and significant but relatively slight differences in allele frequencies between collections were found in one population. Little significant 2-locus linkage disequilibrium was detected and the variances of linkage disequilibrium coefficients were generally consistent with genetic drift. Individual breeding substrates (rotting cactus cladodes) were collected and the adult flies emerging from them were scored for their allozyme genotypes. The data suggest that approximately ten individuals contribute to the progeny emerging from a rot. The influence of the sizes and distributions of breeding substrates on the maintenance of genetic variation is discussed.

\section{INTRODUCTION}

An understanding of the breeding structure of populations is essential for explaining the maintenance of genetic variation, and changes in gene and genotype frequencies over space and time. Breeding structure is the base-line to which various scales of spatial and temporal environmental variation must be related to evaluate their significance in evolution.

Drosophila species have been the subject of many laboratory studies on the effects of spatial and temporal variation on genetic variation (e.g., McDonald and Ayala, 1974; Powell, 1971; Powell and Wistrand, 1978), but most species are not suitable for studies of breeding structure in natural populations because of our general ignorance about their ecology. Members of the mulleri subgroup of the repleta group of Drosophila are a conspicuous exception, because most of them feed and breed exclusively in decaying cactus tissue, often with considerable host specificity (Heed, 1978; Heed, 1982; Heed and Mangan, 1986). One member of the subgroup, D. buzzatii, has spread from South America around the world together

\footnotetext{
* Current address and address for correspondence: Department of Zoology, Natural History Museum, Cromwell Road, London SW7 5BD, U.K.
}

with its host species of Opuntia cactus (Barker and Mulley, 1976). It has a widespread distribution in eastern Australia and provides a powerful model system for studies in ecological genetics (e.g., Barker et al., 1986; Sokal et al., 1987). A long term study of polymorphic allozymes within a single population suggested that microspatial heterogeneity at the level of individual breeding substrates (rots) is very important in maintaining polymorphismns (Barker et al., 1986).

In order to understand the breeding structure of $D$. buzzatii, we investigated the allozyme genotypes of flies emerging from particular rots, and compared them to samples of the population at large. Measures of inbreeding and linkage disequilibrium were calculated, to throw light on breeding structure and to estimate the effective number of parents contributing to the flies emerging from a rot. These measures relate the pattern of matings in a population to breeding substrates, and suggest mechanisms that could maintain the polymorphisms.

\section{METHODS}

Seasonal collections were made at bi-monthly intervals throughout 1986 at two sites in New South 
Wales. These sites are $\mathrm{O}^{\prime} \mathrm{Hara}\left(30^{\circ} 26^{\prime} \mathrm{S}, 150^{\circ} 39^{\prime} \mathrm{E}\right)$, in a paddock in the Hunter River Valley near Denman, and Trinkey $\left(31^{\circ} 22^{\prime} \mathrm{S}, 149^{\circ} 27^{\prime} \mathrm{E}\right)$, located near Tambar Springs, in a transition from paddock to forest edge, approximately $150 \mathrm{~km}$ from O'Hara. Flies were collected from fermenting banana baits, by net or by aspiration. Twenty to thirty baits were spread widely through the habitat and were checked in a circuit until enough flies were obtained or until collecting conditions deteriorated.

Collections from individual rotting cactus cladodes (rots) were made on two occasions from Trinkey, once from O'Hara, and once from each of four sites in southeast Queensland (near Brisbane) viz.: (1) Grandchester $\left(27^{\circ} 40^{\prime} \mathrm{S}, 152^{\circ} 28^{\prime} \mathrm{E}\right)$, (2) Grandchester Hill $\left(27^{\circ} 40^{\prime} \mathrm{S}, 152^{\circ} 28^{\prime} \mathrm{E}\right)$, (3) Borallon $\left(27^{\circ} 31^{\prime} \mathrm{S}, 152^{\circ} 43^{\prime} \mathrm{E}\right)$, and (4) Hemmant $\left(27^{\circ} 27^{\prime} \mathrm{S}, 153^{\circ} 3^{\prime} \mathrm{E}\right)$. Individual rots were maintained in gauze covered containers on moist sand held at $25^{\circ} \mathrm{C}$ and emerging adults were aspirated from them daily.

Six enzyme loci known to be polymorphic in these populations were assayed using the methods of Barker and Mulley (1976) and Barker, East and Weir (1986). Knibb et al. (1987) may be consulted for further information on the scoring of esterase alleles. The loci are esterase-1 (Est-1), esterase-2 (Est-2), $\beta$-N-acetyl-hexosaminidase (Hex), phosphoglucomutase (Pgm), aldehyde oxidase (Aldox), and alcohol dehydrogenase-1 (Adh-1). All these loci are autosomal. Est-1, Est-2 and Aldox are on chromosome II, with Est-1 and Aldox being within a polymorphic inversion $(2 \mathrm{j})$ and $E s t-2$ just beyond the inversion breakpoint (Schafer, personal communication). In the Standard arrangement (2st), Aldox maps between Est-1 and Est-2 $14 \mathrm{cM}$ from Est 1 and $21 \mathrm{cM}$ from Est-2. The $\mathrm{j}$ arrangement order is Aldox, Est-1, Est-2 with Est-1 $37 \mathrm{cM}$ from Est-2 (Schafer, personal communication). Adh-1 and $H e x$ are on chromosome III but show no linkage. $\mathrm{Pgm}$ is on chromosome IV.

\section{Statistical analyses}

\section{Allelic frequencies and F-statistics}

Analyses of allelic frequencies and the calculation of $F$-statistics using the methods of Weir and Cockerham (1984) were accomplished with the program GENSTATS, kindly made available by Krafsur (Black and Krafsur, 1985a). F-statistics were also calculated by Nei's (1977) methods. The use of either method did not alter the qualitative conclusions presented here.
Tests of selective neutrality were performed by the method of Lewontin and Krakauer (1973), where significant heterogeneity among loci in a measure of genetic variation indicates selective differences. This test is based on the idea that genetic drift will affect all loci similarly while selection will affect different regions of the genome differently. Some of the limitations of this test will be discussed later. The measure of genetic variation used here was $F_{\mathrm{ST}}$ and the significance test compared the ratio of the observed variance in $F_{\mathrm{ST}}$ over its expected variance to an $F_{(n-1, \cdot)}$ distribution, where $n$ was the number of sampling periods and the dot indicates an average taken over all alleles at a locus. The observed variance was calculated as,

$$
\mathrm{s}_{\mathrm{F}}^{2}=\sum_{j=1}^{m} \frac{N_{j}}{N}\left(\hat{F}_{\mathrm{ST} . j}-\tilde{F}_{\mathrm{ST}}\right)^{2},
$$

where $N$ is the total sample size and $N_{j}$ is the sample size of the $j$ th locus considered over $m$ loci. The expected variance is,

$$
\sigma_{\mathrm{F}}^{2}=\frac{k \bar{F}_{\mathrm{ST}}^{2}}{(n-1)}
$$

where the parameter $k$ is set equal to 2 (Lewontin and Krakauer, 1973) and $n$ is the number of sampling periods.

\section{Linkage disequilibria}

Analyses of linkage disequilibria were done on a two-allele collapse of the data, so as to eliminate problems due to very small numbers in some genotypic classes. The most common alleles at multiallelic loci were retained and all the others pooled. Diallelic two-locus disequilibrium coefficients were calculated with Cockerham and Weir's (1977) composite measure,

$$
\Delta_{i j}=D_{w}^{i j}+D_{b}^{i j},
$$

where $D_{w}^{i j}$ is the within-gamete disequilibrium component between allele $i$ at locus $A$ and allele $j$ at locus $B$. Similarly, $D_{b}^{i j}$ is the between-gamete disequilibrium component for the same alleles. $\Delta_{i j}$ has the desirable properties of being unbiased with respect to departures from random mating and is usable with genotypic data rather than gametic or haplotype data (Cockerham and Weir, 1977). $\Delta_{i j}$, when normalized by the products of allele frequencies as,

$$
r_{i j}=\Delta_{i j} /\left[\left(p_{i}\left(1-p_{i}\right)+D_{i .}^{i}\right)\left(p_{j}\left(1-p_{j}\right)+D_{. j}^{j}\right)\right]^{1 / 2}
$$


gives the correlation of allele frequencies between the two loci (Weir, 1979). The $D_{i .}^{i .}$ and $D_{j}^{j}$ are measures of departure from Hardy-Weinberg equilibrium at each locus. Tests of the hypothesis that $\Delta_{i j}=0$ were done with the statistic,

$$
X^{2}=N\left(r_{i j}^{2}\right),
$$

where $N$ is the number of individuals sampled. $X^{2}$ is distributed approximately as $\chi^{2}$ with one degree of freedom when considering particular pairs of alleles. For calculating disequilibria between loci the statistic is summed over two-allele interactions as,

$$
X^{2}=N \sum_{i j}\left(\Delta_{i j}^{2} / p_{i} p_{j}\right),
$$

which is also distributed approximately as $\chi^{2}$ with $(m-1)(n-1)$ degrees of freedom, where $m$ and $n$ are the number of alleles at loci $A$ and $B$ respectively (Weir, 1979). Using these tests with the present data, each has one degree of freedom.

The effects of population subdivision on linkage disequilibria were analyzed under the model of Ohta $(1982 b)$ which incorporates a finite island model with extinction and replacement of colonies. Her model partitions the variance of linkage disequilibrium into components in a manner roughly analogous to Wright's partitioning of the inbreeding coefficient using $F$-statistics (Wright, 1969). By comparing five measures of the variance of disequilibrium describing total, within- and betweensubdivision components, Ohta's method (1982a) is able to distinguish between drift due to limited dispersal and epistatic natural selection. These five measures of variance of disequilibrium are: (1) $D_{\mathrm{IT}}^{2}$, total variance of disequilibrium, (2) $D_{\mathrm{IS}}^{2}$, variance of within-subpopulation disequilibrium, (3) $D_{\mathrm{ST}}^{2}$, variance of the correlation of the $i$ th alleles of loci $A$ and $B$ of different gametes of one subpopulation relative to the total population, (4) $D_{\text {IS }}^{\prime 2}$, variance of the correlation between the $i$ th alleles of loci $A$ and $B$ of one gamete of a subpopulation relative to that of the average gamete of the population, and (5) $D_{\mathrm{ST}}^{\prime 2}$, variance of the ordinary disequilibrium of the whole population. Three of these measures are related as,

$$
D_{\mathrm{IT}}^{2}=D_{\mathrm{IS}}^{\prime 2}+D_{\mathrm{ST}}^{\prime 2} \text {. }
$$

When genetic drift resulting from limited migration is primarily responsible for the observed disequilibrium $D_{\mathrm{IS}}^{2}<D_{\mathrm{ST}}^{2}$ and $D_{\mathrm{IS}}^{\prime 2}>D_{\mathrm{ST}}^{\prime 2}$, because the variation among populations is expected to exceed that within populations. When epistatic selection is important for linkage disequilibrium but not for local differentiation, $D_{\mathrm{IS}}^{2}>D_{\mathrm{ST}}^{2}$ and $D_{\mathrm{IS}}^{\prime 2}<D_{\mathrm{ST}}^{\prime 2}$.
This is simply because gametes with favourable combinations of alleles should increase in all colonies. When selection acts, but not systematically, i.e., not in the same direction in each subpopulation, $D_{\mathrm{IS}}^{2}>D_{\mathrm{ST}}^{2}$ and $D_{\mathrm{IS}}^{\prime 2}>D_{\mathrm{ST}}^{\prime 2}$. Ohta $(1982 a, b)$ should be consulted for the derivations of these relationships.

Analyses of linkage disequilibria, and of the effects of population subdivision on the variance of linkage disequilibrium coefficients, were carried out using the program LINKDIS (Black and Krafsur, $1985 b$ ), modified to accommodate larger data sets.

\section{RESULTS}

Data from the seasonal collections, which should represent random samples of the populations from which they were drawn, will be considered first. These samples are the baseline with which to compare the samples emerging from rots, considered in the following section.

\section{Seasonal collections}

Table 1 gives the allele frequencies observed at each locus for each collection. Table 2 shows the alleles with significant frequency differences among collections within sites. Since fewer collections were obtained from Trinkey, it might be thought that the lack of significant temporal variation in the frequencies of common alleles was simply the result of sampling too short a time span. However, when only those collections at directly comparable times from both locations were analyzed, most of the significant variation in allele frequencies at O'Hara remained. Variation in allele frequencies is thus greater in the O'Hara population than in the Trinkey population.

As a conservative test of departures from random mating, chi-square tests for the homogeneity of observed and expected heterozygosities for each locus within a collection were performed. Table 2 gives the proportions of tests which showed significant heterozygote excess or deficiency. Only significant deficiencies were found. Of the possible explanations for this result, inbreeding and the Wahlund effect are the most likely. Seasonal collections in a sense are pooled samples from individual breeding substrates, and the sampling scheme should have included many such substrates. It is therefore difficult to disentangle the effects of inbreeding over the entire population and the Wahlund effect due to the pooling of subdivisions. 
Table 1 Allele frequencies from seasonal collections at two sites (O'Hara and Trinkey) in NSW, with sample sizes ( $N$ )

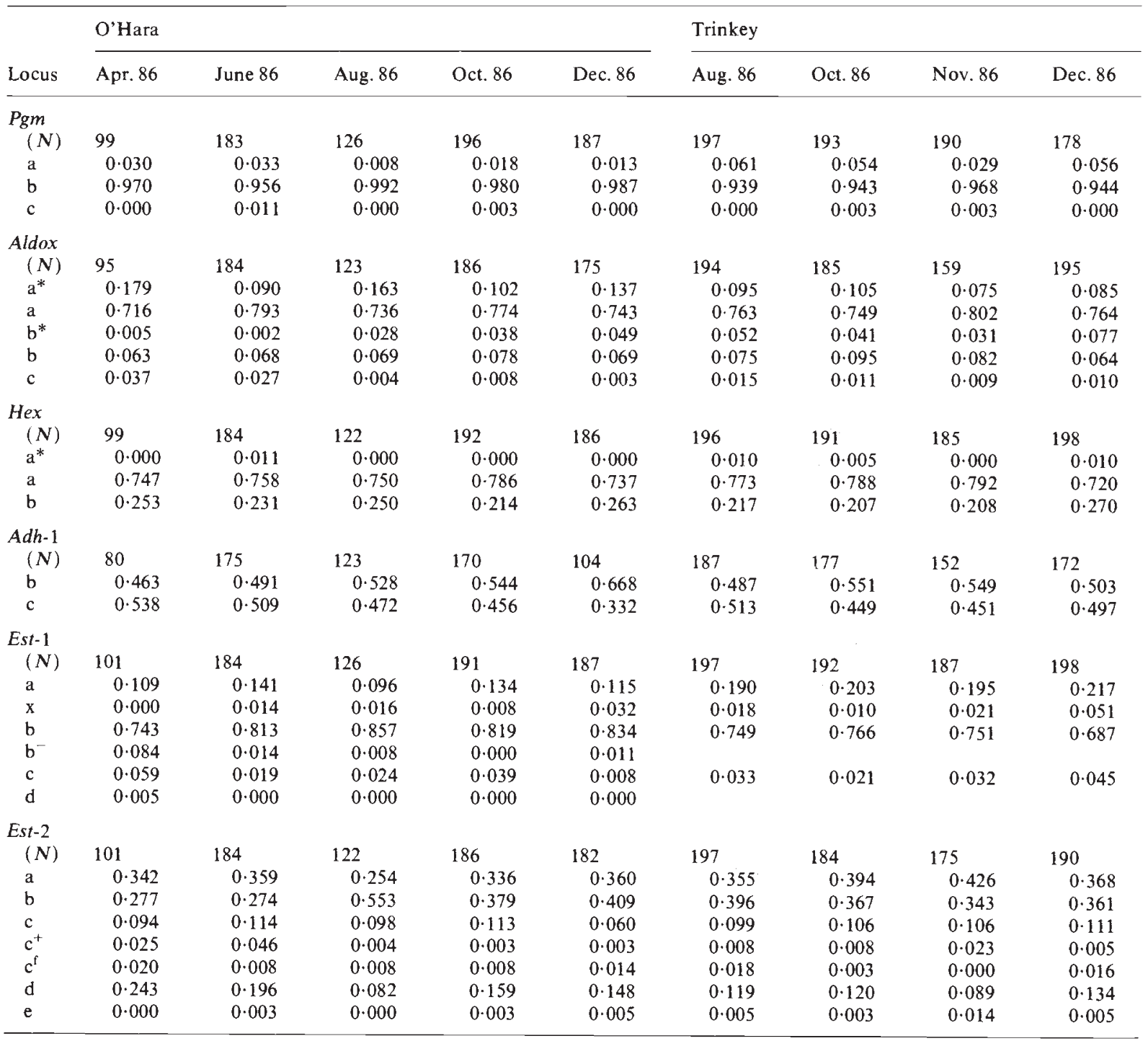

Superscripts on allele designations indicate mobility variants discovered after the non-superscripted alleles had all been named.

Table 3 presents $F$-statistics calculated by the methods of Weir and Cockerham (1984). Both sites exhibited substantial inbreeding over all collections, which was also apparent in individual collections. Differentiation among collections was seen in $F_{\mathrm{ST}}$ values. Trinkey showed very slight differentiation while O'Hara showed more, though still relatively low, differentiation.

Selective differences among loci were tested using Lewontin and Krakauer's (1973) method. There are three assumptions made when applying this test to temporal data (Gaines and Whittam, 1980). First, gene frequency estimates in each sampling period must be based on independent samples. Since samples were taken at intervals of at least two months, different generations were sampled, and so this assumption is met. Secondly, gene frequency distributions in different populations must be identical and unimodal. The observed heterogeneity of allele frequencies at O'Hara violates this assumption. However, this results in the parameter $k$ (equation (1)) being less than two, which biases the test against the rejection of selective neutrality. Finally, Lewontin and Krakauer (1973) state that the number of independent observations for each $\hat{F}_{\mathrm{ST}}$ must be greater 
Table 2 Allozyme alleles showing significant frequency differences $(P<0.05)$ between collections within sites. Square brackets indicate alleles present at frequencies less than 5 per cent. Proportion of seasonal collections from O'Hara and Trinkey showing a significant excess or deficiency of heterozygotes compared to that expected under Hardy-Weinberg proportions $(N=9, P<0.05)$

\begin{tabular}{lllll}
\hline & & & \multicolumn{2}{l}{$\begin{array}{l}\text { Proportion showing } \\
\text { significant }\end{array}$} \\
\cline { 3 - 3 } Locus & Ollele & & Deficiency & Excess \\
\hline Pgm & $\mathrm{b},[\mathrm{c}]$ & & $0 \cdot 11$ & 0 \\
Aldox & $\mathrm{a}^{*},\left[\mathrm{~b}^{*}, \mathrm{c}\right]$ & {$\left[\mathrm{b}^{*}\right]$} & $0 \cdot 22$ & 0 \\
Hex & {$\left[\mathrm{a}^{*}\right]$} & & $0 \cdot 22$ & 0 \\
Adh-1 & $\mathrm{b}, \mathrm{c}$ & & $0 \cdot 11$ & 0 \\
Est-1 & $\mathrm{b},\left[\mathrm{c}, \mathrm{x}, \mathrm{b}^{-}\right]$ & {$[\mathrm{x}]$} & 0.67 & 0 \\
Est-2 & $\mathrm{b}, \mathrm{d},\left[\mathrm{c}^{+}\right]$ & {$\left[\mathrm{c}^{\mathfrak{f}}\right]$} & 0.56 & 0 \\
\hline
\end{tabular}

than eight to detect heterogeneity. O'Hara was sampled five times and Trinkey four times. Trinkey, not surprisingly, showed no heterogeneity among loci $(P>0.05)$. O'Hara, on the other hand, did show significant heterogeneity among loci $(P<$ $0 \cdot 05$ ), suggesting that the allozyme loci, or closely linked regions, are under different selective regimes.

Two-locus linkage disequilibria on a 2-allele collapse of the seasonal data showed few significant values (some were expected by chance) and these had no discernible pattern. Sample sizes within collections were too small to allow much power in these tests, but the results are not surprising given the common observation of very little observed linkage disequilibrium in natural populations of Drosophila (Langley et al., 1978; LaurieAhlberg and Weir, 1979). However, Barker, East and Weir (1986) found significant disequilibrium between Est-2 and Aldox, and Hex and Aldox in D. buzzatii. Examination of variances of linkage disequilibrium coefficients under Ohta's model showed some differences between the populations. At O'Hara the values for all pairs of loci were consistent with drift $\left(D_{\mathrm{IS}}^{2}<D_{\mathrm{ST}}^{2}\right.$ and $\left.D_{\mathrm{IS}}^{\prime 2}>D_{\mathrm{ST}}^{\prime 2}\right)$, while at Trinkey the following pairs suggest selection acting in a nonsystematic manner across loci $\left(D_{\mathrm{IS}}^{2}>D_{\mathrm{ST}}^{2}\right.$ and $\left.D_{\mathrm{IS}}^{\prime 2}>D_{\mathrm{ST}}^{\prime 2}\right):$ Aldox and Est-1, Aldox and Est-2, Adh-1 and Est-2, and Est-1 and Est-2. The remaining pairs of Trinkey loci were consistent with drift. Table 4 lists these variance components for Trinkey collections.

\section{Rot collections}

All collections from all locations showed significant $(P<0 \cdot 05)$ heterogeneity of allele frequencies among rots, probably due to small numbers of "founders". This conclusion was bolstered by the general deficiency of heterozygotes (table 5), except for $A d h-1$, where there was a tendency towards heterozygote excess.

Tables 6-11 present summary $F$-statistics for each collection of rots. $F_{\mathrm{IT}}$ values were significant at all sites and were larger than the seasonal $F_{\mathrm{IT}}$ 's, implying either a nonrandom sample of the population relative to the baited seasonal samples, or the presence of sib-groups in rot emergences (i.e., $N_{\mathrm{e}} \ll N_{0}$, where $N_{0}$ is the census population size). The latter possibility is more likely given the sizes of some collections. $F_{\mathrm{ST}}$ values were significant at all sites and were generally three to ten times those for seasonal collections, indicating substantial differentiation among rots (coancestry within rots).

Analysis of 2-locus linkage disequilibrium coefficients and their partitioned variances revealed interesting patterns. Three pairs of loci, Aldox and Est-1, Est-1 and Est-2, and Hex and Adh-1, showed significant disequilibria considered at the level of rots (table 12). All of these pairs have both members located on the same chromosome, thus this result was probably due simply to

Table 3 F-statistics on four seasonal collections from Trinkey, NSW and five seasonal collections from O'Hara, NSW

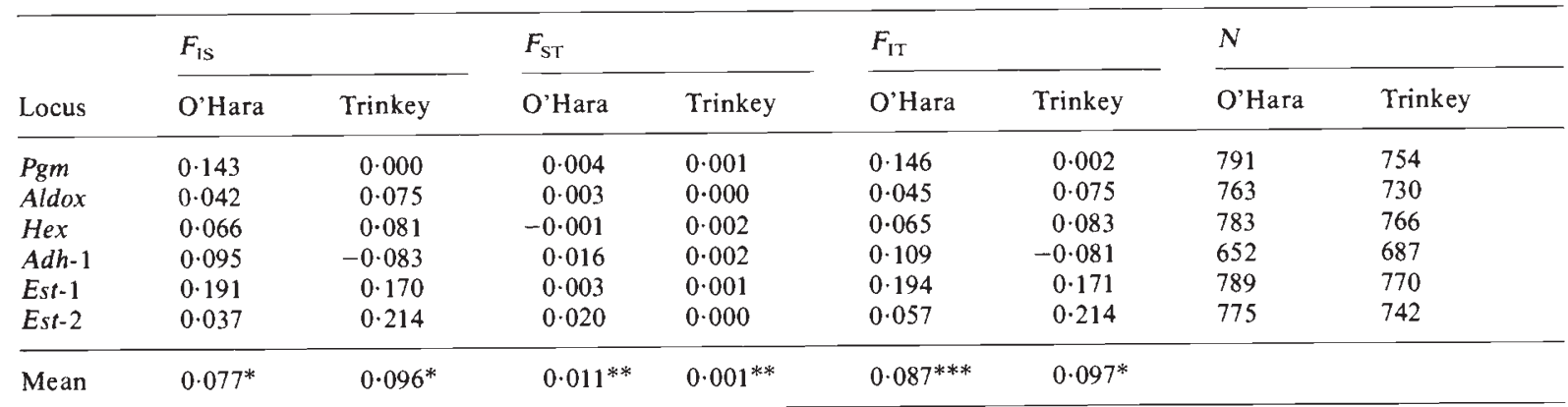

$*, * *$ and $* * *$ indicate statistical difference from zero at probability levels of $0 \cdot 05,0.01$ and 0.001 respectively. 
Table 4 Variance components of linkage disequilibrium coefficients for Trinkey seasonal collections

\begin{tabular}{|c|c|c|c|c|c|}
\hline \multirow[b]{2}{*}{ Loci compared } & \multicolumn{2}{|c|}{$\begin{array}{l}\text { Within subpopulation } \\
\text { components }\end{array}$} & \multicolumn{2}{|c|}{$\begin{array}{l}\text { Between subpopulation } \\
\text { components }\end{array}$} & \multirow{2}{*}{$\begin{array}{l}\text { Total } \\
\text { population } \\
\text { component }\end{array}$} \\
\hline & $D_{\mathrm{IS}}^{2}$ & $D_{\mathrm{IS}}^{\prime 2}$ & $D_{\mathrm{ST}}^{2}$ & $D_{\mathrm{ST}}^{\prime 2}$ & \\
\hline Pgm \& Aldox & 0.00049 & 0.00489 & 0.00111 & 0.00003 & 0.00492 \\
\hline Pgm \& Hex & 0.00008 & 0.00784 & $0 \cdot 00181$ & 0.00000 & 0.00785 \\
\hline$P g m \& A d h-1$ & 0.00025 & 0.00550 & 0.00159 & 0.00015 & 0.00565 \\
\hline Pgm \& Est-1 & 0.00004 & 0.00526 & 0.00187 & $0 \cdot 00002$ & 0.00528 \\
\hline Pgm \& Est-2 & 0.00035 & 0.00532 & $0 \cdot 00135$ & 0.00002 & 0.00534 \\
\hline Aldox \& Hex & 0.00086 & 0.00606 & 0.00168 & 0.00075 & 0.00681 \\
\hline Aldox \& Adh-1 & 0.00039 & 0.00928 & 0.00143 & 0.00010 & 0.00938 \\
\hline Aldox \& Est 1 & 0.00180 & 0.00526 & 0.00167 & 0.00168 & 0.00694 \\
\hline Aldox \& Est-2 & 0.00202 & 0.00455 & 0.00127 & 0.00044 & 0.00500 \\
\hline Hex \& Adh-1 & 0.00042 & 0.00794 & 0.00190 & 0.00012 & 0.00806 \\
\hline Hex \& Est-1 & 0.00095 & 0.00947 & 0.00254 & 0.00000 & 0.00947 \\
\hline Hex \& Est-2 & 0.00019 & 0.00662 & 0.00172 & 0.00001 & 0.00664 \\
\hline Adh-1 \& Est-1 & 0.00177 & 0.00674 & 0.00193 & 0.00000 & 0.00674 \\
\hline Adh-1 \& Est-2 & 0.00257 & 0.00839 & 0.00156 & 0.00000 & 0.00838 \\
\hline Est $-1 \&$ Est -2 & 0.00289 & 0.00844 & 0.00180 & 0.00290 & 0.01134 \\
\hline
\end{tabular}

Table 5 Proportion of rots at four sites in Queensland and at O'Hara and Trinkey in NSW showing a significant excess or deficiency of heterozygotes compared to that expected under Hardy-Weinberg $(N=95, P<0.05)$

\begin{tabular}{lll}
\hline & \multicolumn{2}{l}{ Proportion showing } \\
\cline { 2 - 3 } Locus & Deficiency & Excess \\
\hline Pgm & 0 & 0 \\
Aldox & 0.053 & 0 \\
Hex & 0.084 & 0 \\
Adh -1 & 0.021 & 0.042 \\
Est -1 & 0.189 & 0 \\
Est -2 & 0.263 & 0.011 \\
\hline
\end{tabular}

the relatedness of flies emerging from a rot. The partitioned variances of linkage disequilibrium coefficients were consistent with drift $\left(D_{\mathrm{IS}}^{2}<D_{\mathrm{ST}}^{2}\right.$ and $D_{\mathrm{IS}}^{\prime 2}>D_{\mathrm{ST}}^{\prime 2}$ ) for all pairs of loci and at all sites (tables 13 and 14 give these results for Trinkey and
O'Hara, respectively. All four Queensland sites yield very similar results.). Total variance $\left(D_{\mathrm{IT}}^{2}\right)$ for rots was 10 to 20 times that of seasonal collections-another reflection of small effective population size within rots.

\section{DISCUSSION}

The breeding structure of $D$. buzzatii populations is strongly affected by their discrete and somewhat ephemeral feeding and breeding substrates. In the Australian populations studied, population size is controlled in part by seasonal variation in temperature and in part by the bivoltine life-cycle of the moth Cactoblastis cactorum (Murray, 1982), which generates substantial variation in the amount of rotting cactus tissue available (personal observation). The longevity of a rot, which influen-

Table $6 F$-statistics on adult flies emerging from rots collected at Trinkey, NSW in June $1986(N=4)$ and in December 1986 $(N=5)$. Only rots yielding at least ten individuals were included in the analysis

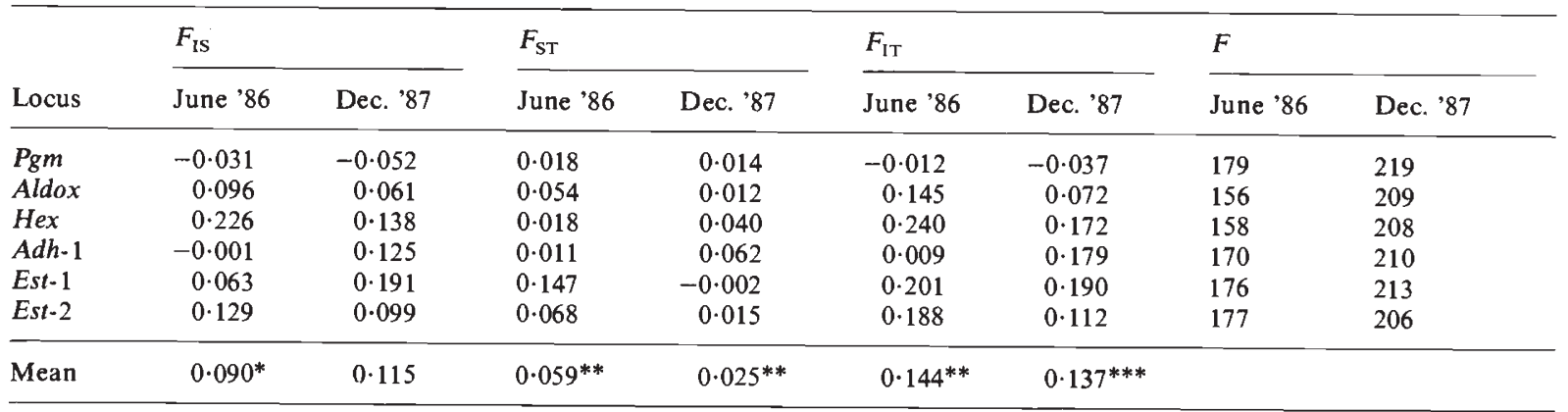

${ }^{*},{ }^{* *}$ and ${ }^{* * *}$ indicate statistical difference from zero at probability levels of $0.05,0.01$ and 0.001 respectively. 
Table $7 F$-statistics on adult flies emerging from seven rots at O'Hara, NSW in June 1986. Only rots yielding at least ten individuals were included in the analysis

\begin{tabular}{lllll}
\hline Locus & $F_{\mathrm{IS}}$ & \multicolumn{1}{l}{$F_{\mathrm{ST}}$} & $F_{\mathrm{IT}}$ & $N$ \\
\hline Pgm & 0.210 & -0.008 & 0.204 & 348 \\
Aldox & 0.086 & -0.001 & 0.085 & 254 \\
Hex & 0.279 & 0.002 & 0.281 & 339 \\
Adh-1 & 0.019 & 0.002 & 0.020 & 329 \\
Est -1 & 0.319 & -0.001 & 0.318 & 341 \\
Est -2 & 0.088 & 0.004 & 0.092 & 344 \\
\hline Mean & 0.143 & $0.002^{*}$ & $0.144^{* *}$ & \\
\hline
\end{tabular}

* and ** indicate statistical difference from zero at probability levels of 0.05 and 0.01 respectively.

Table $8 F$-statistics on adult flies emerging from 26 rots at Grandchester, Queensland in November 1978. Only rots yielding at least ten individuals were included in the analysis

\begin{tabular}{lrlrl}
\hline Locus & \multicolumn{1}{l}{$F_{\mathrm{IS}}$} & \multicolumn{1}{l}{$F_{\mathrm{ST}}$} & \multicolumn{1}{l}{$F_{\mathrm{IT}}$} & $N$ \\
\hline Pgm & 0.005 & 0.058 & 0.063 & 578 \\
Aldox & 0.061 & 0.051 & 0.109 & 578 \\
Hex & -0.095 & 0.024 & -0.069 & 577 \\
Adh -1 & -0.093 & 0.036 & -0.054 & 577 \\
Est -1 & 0.067 & 0.039 & 0.104 & 578 \\
Est-2 & 0.254 & 0.041 & 0.285 & 576 \\
\hline Mean & 0.070 & $0.038^{* * *}$ & $0.106^{*}$ &
\end{tabular}

* and $* * *$ indicate statistical difference from zero at probability levels of 0.05 and 0.001 respectively.

Table $9 F$-statistics on adult flies emerging from five rots at Grandchester Hill, Queensland in November 1978. Only rots yielding at least ten individuals were included in the analysis

\begin{tabular}{lrrrl}
\hline Locus & \multicolumn{1}{l}{$F_{\mathrm{IS}}$} & \multicolumn{1}{l}{$F_{\mathrm{ST}}$} & \multicolumn{1}{l}{$F_{\mathrm{IT}}$} & $N$ \\
\hline Pgm & 0.000 & -0.024 & -0.025 & 104 \\
Aldox & -0.046 & 0.031 & -0.014 & 104 \\
Hex & -0.230 & 0.091 & -0.118 & 104 \\
Adh -1 & -0.082 & 0.045 & -0.033 & 104 \\
Est-1 & 0.247 & -0.007 & 0.242 & 104 \\
Est-2 & 0.071 & 0.099 & 0.163 & 104 \\
\hline Mean & 0.035 & $0.056^{* *}$ & $0.089^{*}$ & \\
\hline
\end{tabular}

* and $* *$ indicate statistical difference from zero at probability levels of 0.05 and 0.01 respectively.

ces the number of generations of flies that can utilize it, is a function of temperature, of the size of the cladode, and most probably of its microflora. Rotting cladodes, both average and large in size, brought back to the laboratory and maintained at $25^{\circ} \mathrm{C}$ remained suitable as substrates for oviposition and larval feeding for three generations or
Table $10 F$-statistics on adult flies emerging from six rots at Borallon, Queensland in November 1978. Only rots yielding at least ten individuals were included in the analysis

\begin{tabular}{lrrrr}
\hline Locus & \multicolumn{1}{l}{$F_{\mathrm{IS}}$} & \multicolumn{1}{l}{$F_{\mathrm{ST}}$} & \multicolumn{1}{l}{$F_{\mathrm{IT}}$} & $N$ \\
\hline Pgm & 0.011 & -0.014 & -0.003 & 90 \\
Aldox & 1.000 & 0.000 & 1.000 & 90 \\
Hex & -0.027 & 0.024 & -0.002 & 90 \\
Adh -1 & 0.173 & 0.043 & 0.208 & 90 \\
Est-1 & 0.189 & 0.034 & 0.217 & 90 \\
Est-2 & 0.176 & 0.067 & 0.232 & 89 \\
\hline Mean & $0.153^{* * *}$ & $0.048^{* * *}$ & $0.193^{* * *}$ & \\
\hline
\end{tabular}

*** indicates statistical difference from zero at a probability level of 0.001 .

Table $11 F$-statistics on adult flies emerging from 38 rots at Hemmant, Queensland in November 1978. Only rots yielding at least ten individuals were included in the analysis

\begin{tabular}{lrlrrr}
\hline Locus & \multicolumn{1}{l}{$F_{\mathrm{IS}}$} & & \multicolumn{1}{l}{$F_{\mathrm{ST}}$} & \multicolumn{1}{l}{$F_{\mathrm{IT}}$} & \multicolumn{1}{l}{$N$} \\
\cline { 1 - 2 } \cline { 5 - 6 } Pgm & 0.005 & & 0.038 & 0.042 & 810 \\
Aldox & 0.238 & & 0.030 & 0.261 & 810 \\
Hex & -0.046 & & 0.026 & -0.019 & 806 \\
Adh -1 & -0.157 & & 0.034 & -0.118 & 809 \\
Est-1 & 0.204 & & 0.060 & 0.252 & 809 \\
Est-2 & 0.142 & & 0.034 & 0.171 & 806 \\
\hline Mean & 0.065 & & $0.037^{* * *}$ & $0.100^{* *}$ & \\
\hline
\end{tabular}

** and $* * *$ indicate statistical difference from zero at probability levels of 0.01 and 0.001 respectively.

Table 12 Proportion of significant $(P<0.05)$ 2-locus linkage disequilibrium coefficients among flies emerging from 94 rots at Trinkey, O'Hara and four sites in Queensland

\begin{tabular}{llllll}
\hline Locus & Aldox & Est-1 & Est-2 & Hex & Adh-1 \\
\hline Pgm & 0 & 0.096 & 0.064 & 0.032 & 0.053 \\
Aldox & & 0.138 & 0.043 & 0.043 & 0.064 \\
Est -1 & & & 0.170 & 0.074 & 0.085 \\
Est -2 & & & & 0.074 & 0.064 \\
Hex & & & & & 0.106 \\
\hline
\end{tabular}

more (unpublished observations). If adult flies tend to stay on suitable substrates rather than to disperse, and rots are 'colonized' by a small effective number of individuals, then the population-wide heterozygote deficiency measured by $F_{\text {IT }}$ could be explained, at least in part, by inbreeding. The among-rot $F_{\mathrm{ST}}$ values suggest moderate levels of movement between rots within a patch of cactus. Experimental studies (Barker et al., 1989) demonstrate the ability of $D$. buzzatii to move short distances (approximately $100 \mathrm{~m}$ ) between cactus patches. In addition, data from several other cactus-utilizing species of repleta group 
Table 13 Variance components of linkage disequilibrium coefficients for Trinkey rots (June 1986)

\begin{tabular}{|c|c|c|c|c|c|}
\hline \multirow[b]{2}{*}{ Loci compared } & \multicolumn{2}{|c|}{$\begin{array}{l}\text { Within subpopulation } \\
\text { components }\end{array}$} & \multicolumn{2}{|c|}{$\begin{array}{l}\text { Between subpopulation } \\
\text { components }\end{array}$} & \multirow{2}{*}{$\begin{array}{l}\text { Total } \\
\text { population } \\
\text { component }\end{array}$} \\
\hline & $D_{\mathrm{IS}}^{2}$ & $D_{\mathrm{IS}}^{\prime 2}$ & $D_{\mathrm{ST}}^{2}$ & $D_{\mathrm{ST}}^{\prime 2}$ & \\
\hline Pgm \& Aldox & $0 \cdot 00036$ & 0.07736 & 0.05705 & 0.00022 & 0.07758 \\
\hline Pgm \& Hex & 0.00241 & 0.03687 & 0.03428 & 0.00177 & 0.03864 \\
\hline Pgm \& Adh-1 & $0 \cdot 00249$ & 0.04338 & 0.02438 & 0.00116 & 0.04454 \\
\hline Pgm \& Est-1 & $0 \cdot 00169$ & $0 \cdot 11160$ & 0.05634 & 0.00000 & $0 \cdot 11160$ \\
\hline Pgm \& Est-2 & 0.00023 & $0 \cdot 15131$ & 0.03560 & 0.00017 & $0 \cdot 15148$ \\
\hline Aldox \& Hex & 0.00075 & 0.06036 & $0 \cdot 06016$ & $0 \cdot 00043$ & 0.06079 \\
\hline Aldox \& Adh-1 & 0.01907 & $0 \cdot 06428$ & 0.04470 & 0.00921 & 0.07349 \\
\hline Aldox \& Est-1 & $0 \cdot 00806$ & $0 \cdot 13793$ & 0.07254 & 0.00196 & $0 \cdot 13989$ \\
\hline Aldox \& Est-2 & 0.01244 & $0 \cdot 17293$ & 0.06033 & $0 \cdot 00234$ & $0 \cdot 17527$ \\
\hline Hex \& Adh-1 & 0.00866 & 0.04564 & 0.03057 & 0.00200 & 0.04764 \\
\hline Hex \& Est-1 & $0 \cdot 00636$ & $0 \cdot 10366$ & $0 \cdot 05687$ & $0 \cdot 00000$ & $0 \cdot 10367$ \\
\hline Hex \& Est-2 & 0.02924 & $0 \cdot 14304$ & 0.04283 & 0.00914 & $0 \cdot 15217$ \\
\hline Adh-1 \& Est-1 & 0.00829 & $0 \cdot 10047$ & $0 \cdot 04331$ & $0 \cdot 00028$ & $0 \cdot 10075$ \\
\hline Adh-1 \& Est-2 & 0.00265 & $0 \cdot 11102$ & 0.03098 & $0 \cdot 00000$ & $0 \cdot 11102$ \\
\hline Est-1 \& Est-2 & 0.01189 & $0 \cdot 20591$ & 0.05336 & 0.00892 & $0 \cdot 21483$ \\
\hline
\end{tabular}

Drosophila suggest a strong tendency for the flies to remain on suitable substrates (Johnston and Heed, 1975; Johnston and Heed, 1976; Johnston and Templeton, 1982; Templeton and Johnston, 1982; Thomas, unpublished observations).

Analysis of the allozyme genotypes of flies emerging from rots collected from nature are consistent with a small number of "founders" on each substrate. Significant heterogeneity of allozyme frequencies is observed among rots collected in an area of less than 1 hectare, and there is generally a deficiency of heterozygotes relative to Hardy-
Weinberg proportions (the exception is $A d h-1$, where there is a tendency towards an excess of heterozygotes).

Values of $F_{\mathrm{ST}}$, a measure of coancestry, are significantly greater than zero in all collections of rots from all sites and are three to ten or more times the values for the seasonal collections, indicating substantial differentiation among rots within sites. Analysis of 2-locus disequilibria for rot emergences reveals significant "disequilibria" between the pairs Aldox and Est-1, Est-1 and Est-2, and Hex and Adh-1. In the seasonal collec-

Table 14 Variance components of linkage disequilibrium coefficients for O'Hara rots (June 1986)

\begin{tabular}{|c|c|c|c|c|c|}
\hline \multirow[b]{2}{*}{ Loci compared } & \multicolumn{2}{|c|}{$\begin{array}{l}\text { Within subpopulation } \\
\text { components }\end{array}$} & \multicolumn{2}{|c|}{$\begin{array}{l}\text { Between subpopulation } \\
\text { components }\end{array}$} & \multirow{2}{*}{$\begin{array}{l}\text { Total } \\
\text { population } \\
\text { component } \\
D_{\mathrm{IT}}^{2}\end{array}$} \\
\hline & $D_{\mathrm{IS}}^{2}$ & $D_{\mathrm{IS}}^{\prime 2}$ & $D_{\mathrm{ST}}^{2}$ & $D_{\mathrm{ST}}^{\prime 2}$ & \\
\hline Pgm \& Aldox & 0.00052 & 0.01631 & 0.00899 & 0.00020 & 0.01650 \\
\hline Pgm \& Hex & 0.00095 & 0.01560 & 0.00663 & 0.00037 & 0.01597 \\
\hline Pgm \& Adh-1 & 0.00050 & 0.01923 & 0.01095 & $0 \cdot 00016$ & 0.01939 \\
\hline Pgm \& Est-1 & 0.00018 & 0.01699 & 0.01026 & 0.00006 & 0.01705 \\
\hline Pgm \& Est -2 & 0.00074 & 0.02484 & 0.01087 & 0.00031 & 0.02515 \\
\hline Aldox \& Hex & 0.00210 & 0.01805 & 0.00929 & 0.00035 & $0 \cdot 01840$ \\
\hline Aldox \& Adh-1 & 0.00205 & 0.01943 & 0.01027 & 0.00006 & 0.01949 \\
\hline Aldox \& Est-1 & 0.00247 & 0.02051 & 0.01306 & 0.00002 & 0.02053 \\
\hline Aldox \& Est-2 & 0.00114 & 0.02345 & 0.01067 & 0.00008 & 0.02361 \\
\hline Hex \& Adh-1 & 0.00470 & 0.01979 & 0.00858 & 0.00049 & 0.02028 \\
\hline Hex \& Est -1 & 0.00878 & 0.02198 & 0.00982 & 0.00080 & 0.02278 \\
\hline Hex \& Est -2 & 0.00322 & 0.02331 & 0.01087 & 0.00182 & 0.02513 \\
\hline Adh-1 \& Est 1 & 0.00507 & 0.02426 & 0.01067 & 0.00002 & 0.02428 \\
\hline Adh-1 \& Est-2 & 0.00654 & 0.02985 & $0 \cdot 01046$ & 0.00144 & 0.03130 \\
\hline Est $-1 \&$ Est -2 & 0.00153 & 0.02029 & 0.01227 & 0.00024 & 0.02053 \\
\hline
\end{tabular}


tions, however, these pairs do not show significant disequilibria. The members of each pair are located on the same chromosome, though Hex and Adh-1 show no linkage. This suggests that a small number of founders is responsible for the flies emerging from a rot.

Ohta (1982a) provides a model with which to subdivide the variance of linkage disequilibrium, in a manner analogous to the partitioning of $F$ statistics and of the inbreeding coefficient. She assumes Wright's (1969) island model of population structure, an assumption that, at the scale applied here, seems reasonable. By comparing various within and between subpopulation components of variance of disequilibrium, it is possible to distinguish drift due to limited dispersal, systematic epistatic selection and unequal systematic disequilibrium where selection for specific allele pairs occurs in only a few subpopulations. Results for pairs of loci from each collection of rots are consistent with drift due to limited dispersal. Total variance of disequilibrium within each collection of rots is 10 to 20 times that of the seasonal collections. Given that the number of individuals sampled over all the rots in a collection is large, these results are another indication of the small effective population sizes within rots.

What is the genetically effective number of individuals contributing to the progeny emerging from a rot? There are a numnber of factors that complicate attempts to answer this question rigorously. If a small number of males and females contribute to a rot, we expect the sexes to differ in their gene frequencies (Robertson, 1965) which would result in their progeny showing an excess of heterozygotes. This effect could easily be masked by the inbreeding that occurs at the level of rots. Possible selective differences resulting from the ageing of rots between generations may well be a factor also, as mentioned below. Crude estimates of $N_{\mathrm{e}}$, using $F_{\mathrm{ST}}$, under the assumptions of the island model with high migration rates, suggest that about ten individuals contribute gametes to reach rot.

Selection almost certainly influences the fate of alleles at these loci and closely linked regions. Ruiz et al. (1986) showed that viability selection on rearrangements of the second chromosome was operating in opposite directions at different stages of the life-cycle. Est-1, Est-2 and Aldox are located in or near the second chromosome arrangements, but Knibb and Barker (1988) have shown that apparent selection affecting allele frequencies at Est -2 cannot be explained by selection acting on the chromosome arrangements. It is likely, but remains to be demonstrated, that there are selective differences between rots. Thomas (unpublished) has shown that rots vary in the quality of nutrition that they provide for larvae in nature. The microflora differs from rot to rot (Barker et al., 1984) and there is genetic variation in the flies' preferences for oviposition sites (Barker et al., 1986; Barker unpublished). It is not known if there is genetic variation among larvae in their preferences for food, but they do discriminate between yeasts (Barker et al., 1988).

Birley and Haley (1987) have recently investigated gametic disequilibria in populations of $D$. melanogaster of recent natural origin. Using caged populations with three food media, they simulated fine-scale spatial variation of the environment, and counted the allozyme genotypes in cages with various combinations of environments. Their results demonstrate epistatic selection in response to a novel environment, and show that this is not due to isolation between subpopulations. Rather the observed gametic disequilibria are produced by natural selection in the overall cage environment. Thus, even without any tendency to remain on suitable substrates, the observed spatial variation in the environment of $D$. buzzatii could well be exerting epistatic natural selection on the populations.

Hoffmann and Nielsen (1985) have investigated a model of polymorphisms in a situation like that found in $D$. buzzatii. To maintain a polymorphic balance, the model requires a positive correlation between fitness and the amount of genetic variation present in the individuals within a substrate. Inspiration for this model comes in part from experiments comparing the number of progency emerging from pure and mixed cultures (Beardmore, 1963; Kojima and Haung, 1972; Marinkovic and Ayala, 1975; Perez-Tomé and Toro, 1982). All these studies indicate an association between fitness and the amount of genetic variation present. A plausible possibility in the case of $D$. buzzatii is that the use of resources in a rot is more efficient, when more genetically variable larvae are present. The values of $F_{\mathrm{ST}}$ observed in the present study are consistent with about five pairs contributing to each rot. While this number is believable, it remains to be determined if the model is appropriate.

In conclusion, our data show that a small number of individuals contribute progency to a given rot. Other studies suggest that this sort of population structure is very common, especially among insects (e.g., Hoffmann and Nielsen, 1985; Lacy, 1983). Measures of inbreeding strongly suggest 
that flies mate within rots, thereby making mating non-random in the population as a whole. This is consistent with ecological observations on related species of Drosophila, showing that flies tend to remain on suitable substrates rather than dispersing to new substrates. Such conditions could make habitat selection a potent force in maintaining genetic variation in $D$. buzzatii. It remains to show directly the importance of habitat selection. Experiments to distinguish the effects on the maintenance of genetic variation of resource subdivision per se and spatial heterogeneity in the composition of those resources are needed.

Acknowledgements Darren Schafer's good humoured help with field and laboratory work is much appreciated. Chris Leger and Jenny Druitt ran many gels and also maintained their senses of humour, for which we thank them. Wayne Knibb and Bryan Clarke provided useful comments. This work was supported by a grant from the Australian Research Grants Scheme to J.S.F.B.

\section{REFERENCES}

BARKER, J. S. F., CHRISTIANSEN, F. B. AND EAST, P. D. 1989. Estimation of migration from a perturbation experiment in natural populations of Drosophila buzzatii. Biol. J. Linn. Soc., 37, 311-334.

BARKER, J. S. F., EAST, P. D. PHAFF, H. J. AND MIRANDA, M. 1984. The ecology of the yeast flora in necrotic Opuntia cacti and of associated Drosophila in Australia. Microb. Ecol., 10, 379-399.

BARKER, J. S. F., EAST, P. D. AND WEIR, B. S. 1986. Temporal and microgeographic variation in allozyme frequencies in a natural population of Drosophila buzzatii. Genetics, 112, $577-611$.

BARKER, J. S. F. AND MULLEY, J. C. 1976. Isozyme variation in natural populations of Drosophila buzzatii. Evolution, 30, 212-233.

BARKER, J. S. F., VACEK, D. C. AND EAST, P. D. 1988. Attraction of larvae of Drosophila buzzatii and $D$, aldrichi to yeast species isolated from their natural environment. Aust. J. Zool., 36, 53 63.

BARKER, J. S. F., VACEK, D. C., EAST, P. D. AND STARMER, W. T. 1986 Allozyme genotypes of Drosophila buzzatii: Feeding and oviposition preferences for microbial speci-s, and habitat selection. Aust. J. Biol. Sci., 39, 47-58.

BEARDMORE, J. A. 1963. Mutual facilitation and the fitness of polymorphic populations. Amer. Natur., 97, 69-74.

BIRLEY, A. J. AND HALEY, C. S. 1987. The genetical response to natural selection by varied environments. Genetics, 115 , 295-303.

BLACK, W. C. AND KRAFSUR, E. S. 1985a. A FORTRAN program for analysis of genotypic frequencies and description of the breeding structure of populations. Theor. Appl. Genet. 70. 484-490.

BLACK, W. C. AND KRAFSUR, E. S. 1985b. A FORTRAN program for the calculation and analysis of two-locus linkage disequilibrium coefficients. Theor. Appl. Genet., 70, 491496.
COCKerham, C. C. AND WeIR, B. S. 1977. Digenic descent measures for finite populations. Genet. Res., 30, 121-147.

GAINES, M. S. AND WHITTAM, T. S. 1980. Genetic changes in fluctuating vole populations: Selective vs. nonselective forces. Genetics, 96, 767-778.

HEED, W. B. 1978. Ecology and genetics of Sonoran Desert Drosophila, In Brussard, P. F. (ed.) Ecological Genetics: The Interface, Springer-Verlag, New York, pp. 109-126.

HEED, W. B. 1982. The origin of Drosophila in the Sonoran Desert, In Barker, J. S. F. and Starmner, W. T. (eds) Ecological Genetics and Evolution: The Cactus-YeastDrosophila Model System, Academic Press Australia, Sydney, pp. 65-80.

HEED, W. B. AND MANGAN, R. L.1986. Community ecology of the Sonoran Desert Drosophila, In Ashburner, M., Carson, H. L. and Thompson, J. N. (eds) The Genetics and Biology of Drosophila, Academic Press, New York.

HOFFMANN, A. A. AND NIELSEN, K. M. 1985. The effect of resource subdivision on genetic variation in Drosophila. Amer. Natur., 125, 421-430.

JOHNSTON, J. S. AND HEED, W. B. 1975. Dispersal of Drosophila the effect of baiting on the behavior and distribution of natural populations. Amer. Natur., 108, 207-216.

JOHNSTON, J. S. AND HEED, W. B. 1976. Dispersal of desertadapted Drosophila: the saguaro-breeding $D$. nigrospiracula. Amer. Natur., 110, 629-651.

JOHNSTON, J. S. AND TEMPLETON, A. R. 1982. Dispersal and clines in Opuntia breeding Drosophila mercatorum and $D$. hydei at Kamuela, Hawaii, In Barker, J. S. F. and Starmer, W. T. (eds) Ecological Genetics and Evolution. The CactusYeast-Drosophila Model System, Academic Press Australia, Sydney.

KNIBB, W. R. AND BARKER, J. S. F. 1988. Polymorphic inversion and esterase loci complex on chromosome 2 of Drosophila buzzatii. II. Spatial variation. Aust. J. Biol. Sci., 41, 239-246.

KNIBB, W. R., EAST, P. D. AND BARKER, J. S. F. 1987, Polymorphic inversion and esterase loci complex on chromosomne 2 of Drosophila buzzatii. I. Linkage disequilibrium. Aust. J. Biol. Sci., 40, 257-269.

KOJIMA, K. AND HAUNG, S. L. 1972. Effects of population density on the frequency-dependent selection in the esterase-6 locus of Drosophila melanogaster. Evolution, 26, 313-321.

LACY, R. 1983. Structure of genetic variation within and between populations of mycophagous Drosophila. Genetics, 104, 81-94.

LANGLEY, C. H., SMITH, D. B. AND JOHNSON, F. M. 1978. Analysis of linkage disequilibria between allozyme loci in natural populations of Drosophila melanogaster. Genet. Res., Camb., 32, 215-229.

LAURIE-AHLberG, C. C. AND Weir, B. S. 1979. Allozymic variation and linkage disequilibrium in some laboratory populations of Drosophila melanogaster. Genetics, 92, 1295-1314.

LEWONTIN, R. C. AND KRAKAUER, J. 1973. Distribution of gene frequency as a test of the theory of the selective neutrality of polymorphisms. Genetics, 74, 175-195.

MARINKOVIC, D. AND AYALA, F. J. 1975. Fitness of allozyme variants in Drosophila pseudoobscura. I. Selection at the Pgm-1 and Me-2 loci. Genetics, 79, 85-95.

McDONALD, J. F. AND AyAlA, F. J. 1974. Genetic response to environmental heterogeneity. Nature, 250, 572-574.

MURRAY, N. D. 1982. Ecology and evolution of the OpuntiaCactoblastis ecosystem in Australia. In Barker, J. S. F. and Starmer, W. T. (eds) Ecological Genetics and Evolution. The Cactus-Yeast-Drosophila Model System, Academic Press Australia, Sydney. 
NEI, M. 1977. F-statistics and analysis of gene diversity in subdivided populations. Ann. Hum. Genet., 41, 225-233.

OHTA, T. 1982a. Linkage disequilibrium due to random genetic drift in finite subdivided populations. Proc. Natl Acad. Sci. USA, 79, 1940-1944.

OHTA, T. 1982 b. Linkage disequilibrium with the island model. Genetics, 101, 139-155.

PEREZ-TOMÉ, J. M. AND TORO, M. A. 1982. Competition of similar and non-similar genotypes. Nature, 299, 153-154.

POWELL, J. R. 1971. Genetic polymorphism in varied environments. Science, 174, 1035-1036.

POWELL, J. R. AND WISTRAND, H. 1978. The effect of heterogeneous environments and a competitor on genetic variation in Drosophila. Amer. Natur., 112, 935-947.

ROBERTSON, A. 1965. The interpretation of genotypic ratios in domestic animal populations. Anim. Prod., 7, 319-324.

RUiz, A., FONTDEVILA, A., SANTOS, M., SEOANE, M. AND TORROJA, E. 1986. The evolutionary history of Drosophila buzzatii. VIII. Evidence for endocyclic selection acting on the inversion polymorphism in a natural population. Evolution, 40,740-755.
SOKAL, R. R., ODEN, N. L. AND BARKER, J. S. F. 1987. Spatial structure in Drosophila buzzatii populations: simple and directional spatial autocorrelation. Amer. Natur., 129, 122142.

TEMPLETON, A. R. AND JOHNSTON, J. S. 1982. Life history evolution under pleiotropy and $\mathrm{K}$-selection in a natural population of Drosophila mercatorum, In Barker, J. F. S. and Starmer, W. T. (eds) Ecological Genetics and Evolution. The Cactus-Yeast-Drosophila Model System, Academic Press Australia, Sydney.

WEIR, B. S. 1979. Inferences about linkage disequilibrium. Biometrics, 35, 235-254.

WEIR, B. S. AND COCKERHAM, C. C. 1984. Estimating $F$-statistics for the analysis of population structure. Evolution, 38 , 1358-1370.

WRIGHT, S. 1969. Evolution and the Genetics of Populations: II. The Theory of Gene Frequencies, University of Chicago Press, Chicago. 